\title{
CONTROLE DO TRIPES-DO-PRATEAMENTO EM CULTIVARES DE AMENDOIM: EFEITOS NOS PARÂMETROS FISIOLÓGICOS E PRODUTIVOS
}

Tamiris Marion de Souza ${ }^{1}$; Marcos Doniseti Michelotto²; Cíntia Michele Ferreira Mendes ${ }^{3}$; Willians César Carrega ${ }^{4}$; Antonio Carlos Busoli ${ }^{5}$ Ignácio José Godoy ${ }^{6}$

${ }^{1}$ Pós-graduanda em Agronomia (Entomologia Agrícola), FCAV/Unesp, Jaboticabal, SP, tamirismdsouza@hotmail.com; ${ }^{2} \mathrm{PqC}$., Bolsista Produtividade CNPq, Apta, Polo Centro Norte, Pindorama, SP; ${ }^{3}$ Graduanda em Agronomia, Unirp, São José do Rio Preto, SP;4Doutor em Agronomia (Produção Vegetal), FCAV/UNESP, Jaboticabal, SP ;5Docente do Departamento de Fitossanidade, FCAV/Unesp;6Pesquisador Cientico, Dr., IAC - Centro de Grãos e Fibras

RESUMO: O objetivo do trabalho foi avaliar os parâmetros fisiológicos e produtivos em duas cultivares de amendoim sob diferentes controles de Enneothrips flavens. O experimento foi instalado em campo, na safra 2017/2018, em área experimental da Apta, Polo Regional Centro Norte, no município de Pindorama, SP. O experimento foi em blocos casualizados, em esquema fatorial $2 \times 4$, com 4 repetições. O primeiro fator correspondeu a duas cultivares de amendoim (IAC 503 e IAC OL3) e o segundo fator, aos controles (1. Testemunha, 2. Silício via foliar, 3. Silício via solo e 4. Inseticida Sintético). As aplicações de silício não induziram resistência satisfatória nas plantas de amendoim para controle do E. flavens; A cultivar IAC 503 apresenta menor número de tripes em relação a cultivar IAC OL3; O inseticida sintético apresenta o melhor controle do tripes e os melhores índices de clorofila, porcentagem de aproveitamento da radiação fotossinteticamente ativa e produtividade;

Palavras-Chave: Arachis hypogaea L., silício, pragas, resistência de planta a inseto.

\section{INTRODUÇÃO}

Na safra 2017/18, o cultivo do amendoim (Arachis hypogaea L.) em áreas de renovação de cana-de-açúcar esteve muito presente, proporcionando crescimento nas áreas cultivadas de $14 \%$, com um aumento de produtividade de 2,8\% em relação à safra 2016/17 (CONAB, 2018).

Um dos principais fatores que comprometem a produtividade da cultura do amendoim é a presença de pragas. Dentre elas, destacam-se o tripes-do-prateamento (Enneothrips flavens Moulton, 1941) (Thysanoptera:Thripidae) e a lagarta-do-pescoço-vermelho (Stegasta bosquella Chambers, 1875) (Lepidoptera: Gelechiidae) (MICHELOTTO et al., 2015).

Para diminuir a dependência de controle químico que oneram os custos de produção e podem contaminar o ambiente, o uso de substâncias que aumentem a resistência das plantas aos insetos é benéfico. Dessa forma, o silício tem se mostrado potencialmente interessante para tal finalidade, uma vez que, de forma indireta, promove modificações anatômicas, morfológicas e fisiológicas nas plantas, atuando como promotor de indução a resistência às pragas, estresses bióticos e abióticos 
(RODRIGUES et al., 2011), proporcionando melhor absorção de nutrientes, aumento no teor de clorofila e na redução da transpiração, possibilitando efeitos positivos na eficiência fotossintética, promovendo, consequentemente, aumentos de produtividade. Diante disso, o objetivo deste trabalho foi avaliar os parâmetros fisiológicos e produtivos em duas cultivares de amendoim sob diferentes controles de Enneothrips flavens.

\section{MATERIAL E MÉTODOS}

O experimento foi instalado na safra 2017/2018, em área experimental da Apta, Polo Regional Centro Norte, no município de Pindorama, SP. O delineamento experimental adotado foi o de blocos casualizados $(\mathrm{DBC})$ em esquema fatorial $2 \times 4$, com 4 repetições. O primeiro fator correspondeu às cultivares de amendoim (IAC OL3 e IAC 503), e o segundo fator, correspondeu aos manejos adotados para controle de pragas: 1. Ausente de controle; 2. Pulverização de silício via foliar; 3. Aplicação de silício via solo; 4. Pulverização de Inseticida Sintético.

Cada unidade experimental foi constituída por 4 linhas de 5 metros e espaçamento entre linhas de $0,90 \mathrm{~m}$. A densidade de semeadura adotada foi de 20 sementes por metro realizada manualmente. Para evitar a interferência de patógenos, as sementes foram previamente tratadas com o fungicida Vitavax ${ }^{\circledR}$-Thiram $200 \mathrm{SC}$ (carboxina + thiram) na dose de $250 \mathrm{~mL}$ do p.c. $/ 100 \mathrm{~kg}^{-1}$ de sementes.

No decorrer do desenvolvimento das cultivares, foram realizadas aos 15, 28, 40, 49, 58, 69, 78 e 91 dias após a emergência (DAE) avaliações contabilizando o número de E. flavens presente em 20 folíolos, ainda fechados.

A aplicação do silício via solo realizou-se por meio da utilização do Silicato de Cálcio (Empresa Agronelli®) na dose de $2.608 \mathrm{~kg} \mathrm{ha}^{-1}\left(23 \% \mathrm{de} \mathrm{SiO}_{2} ; 41 \% \mathrm{CaO} ; 11 \% \mathrm{MgO}\right)$ aplicado a lanço e incorporado manualmente com o auxílio de enxada. Para isolar o efeito do silício, as demais parcelas receberam Calcário Magnesiano na dose de $2.608 \mathrm{~kg} \mathrm{ha}^{-1}(41 \% \mathrm{CaO} ; 11 \% \mathrm{MgO})$ aplicado e incorporado da mesma forma. Ambos foram aplicados 30 dias antes da semeadura.

A aplicação do silício via foliar realizou-se por meio da pulverização utilizando o produto Supa Sílica ${ }^{\circledR}\left(\right.$ Empresa Agrochem $\left.{ }^{\circledR}\right)\left(\right.$ dosagem de 2,0 $\left.\mathrm{L} \mathrm{ha}^{-1}\right)$, a cada 15 dias, totalizando 8 aplicações. A aplicação de inseticida sintético utilizando o produto Pirate ${ }^{\circledR}$ (dosagem de $0,60 \mathrm{~L} \mathrm{ha}^{-1}$ ) foi realizada quando as cultivares atingiram o nível de controle durante as avaliações, ou seja, quando $30 \%$ de folíolos amostrados na parcela continham a presença de ninfas e adultos de E. flavens. Foram realizadas cinco pulverizações aos 17, 30, 40, 50, 79 e 96 DAE no cultivar IAC 503 e cinco pulverizações aos 17, 30, 58, 70, e 96 DAE no cultivar IAC OL 3. Utilizou-se nas aplicações de silício e de inseticida um pulverizador costal com capacidade de $10 \mathrm{~L}$, calibrado para aplicar um volume de $300 \mathrm{~L} \mathrm{ha}^{-1}$ de calda e ponta de pulverização do tipo leque.

$\mathrm{O}$ controle de doenças e das plantas daninhas foram realizadas de acordo com as recomendações para a cultura. 
No dia 01/03/2018, aos 70 DAE, realizou-se a avaliação de clorofila total, expressa em $\mu$ mol $\mathrm{m}^{-2}$, com o auxílio de um Clorofilômetro; avaliação da interceptação da radiação fotossinteticamente

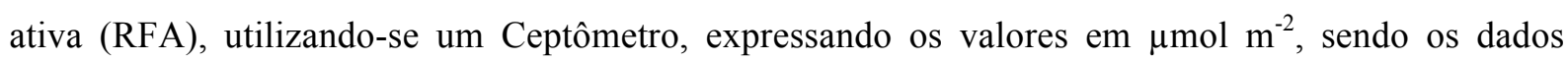
apresentados em porcentagem de aproveitamento da radiação fotossinteticamente ativa (\%ARFA) pela cultura. Além disso, avaliou-se as doenças verrugose (Sphaceloma arachidis) aos 58 DAE e manchapreta (Cercosporidium personatum) aos 91 DAE.

Os dados foram analisados e transformados em raiz $(x+0,5)$ quanto e as médias comparadas pelo teste de Turkey ao nível de $5 \%$ probabilidade.

\section{RESULTADOS E DISCUSSÃO}

Para o número de E. flavens, constatou-se a presença do inseto durante todo o período experimental, contudo, entre os 15 e 69 dias após emergência (DAE) não houve interação entre as cultivares e controles (Tabela 1).

Analisando os efeitos entre as cultivares, sem considerar a interação entre os fatores, verificou-se diferenças entre as cultivares aos 28 e 58 DAE. Nessas épocas, verificou-se que a cultivar IAC 503 apresentou menor número de E. flavens, quando comparado com a cultivar IAC OL3. Entre os controles, também foram observadas diferenças significativas que ocorreram aos 28, 40, 49, 69 DAE. Nessas épocas, o uso do inseticida sintético foi o que apresentou as melhores respostas. Aos 40 DAE, o tratamento com silício aplicado ao solo também diferiu dos tratamentos com silício aplicado via foliar e do ausente de controle, porém não foi melhor que o tratamento com inseticida sintético (Tabela 1).

Tabela 1. Números de E. flavens em 20 folíolos em cultivares de amendoim submetidos a diferentes controles, nas avaliações descritas abaixo. Pindorama, SP, safra 2017/18.

\begin{tabular}{|c|c|c|c|c|c|c|c|c|}
\hline Cultivares (C) & $15 \mathrm{DAE}$ & $28 \mathrm{DAE}$ & $40 \mathrm{DAE}$ & 49DAE & $58 \mathrm{DAE}$ & $69 \mathrm{DAE}$ & $78 \mathrm{DAE}$ & $91 \mathrm{DAE}$ \\
\hline IAC OL3 & 13,9 & $18,2 \mathrm{a}$ & 13,8 & 15,7 & $15,3 \mathrm{a}$ & 28,2 & 16,7 & 19,9 \\
\hline IAC 503 & 11,9 & $13,6 \mathrm{~b}$ & 16,1 & 13,3 & $10,3 \mathrm{~b}$ & 28,5 & 16,6 & 13,8 \\
\hline Média & 12,9 & 15,9 & 14,9 & 14,5 & 12,8 & 27,8 & 16,6 & 16,9 \\
\hline Teste F & $0,93^{\text {ns }}$ & $6,39 *$ & $1,75^{\mathrm{ns}}$ & $1,49^{\text {ns }}$ & $7,39 *$ & $0,08^{\mathrm{ns}}$ & $0,18^{\mathrm{ns}}$ & $11,12 * *$ \\
\hline \multicolumn{9}{|c|}{ Tipos de Controles $(\mathrm{T})$} \\
\hline Ausente & 13,4 & $23,5 \mathrm{a}$ & $23,6 \mathrm{a}$ & $22,5 \mathrm{a}$ & 13,8 & $37,3 \mathrm{a}$ & 23,3 & 18,5 \\
\hline Silício via foliar & 11,3 & $20,3 \mathrm{a}$ & $20,4 \mathrm{a}$ & $17,5 \mathrm{a}$ & 12,1 & 38,8 a & 19,0 & 20,8 \\
\hline Silício via solo & 14,4 & $15,1 \mathrm{a}$ & $12,1 \quad b$ & $14,5 \mathrm{a}$ & 16,0 & $31,5 \mathrm{a}$ & 18,4 & 17,4 \\
\hline Inseticida Sintético & 12,5 & $4,8 \mathrm{~b}$ & 3,6 & $3,5 \mathrm{~b}$ & 9,1 & $4,6 \mathrm{~b}$ & 5,9 & 10,9 \\
\hline Teste F & $0,81 \mathrm{~ns}$ & $18,28 * *$ & $35,11^{* *}$ & $24,21 * *$ & $2,76^{\mathrm{ns}}$ & $40,50 * *$ & $10,95 * *$ & $5,86 * *$ \\
\hline Teste F (C X T) & $0,63^{\text {ns }}$ & $0,09^{\text {ns }}$ & $1,73^{\text {ns }}$ & $1,77^{\mathrm{ns}}$ & $2,94^{\mathrm{ns}}$ & $1,41^{\mathrm{ns}}$ & $3,75^{*}$ & $7,32 * *$ \\
\hline C.V $(\%)$ & 22,04 & 20,42 & 17,38 & 18,40 & 26,16 & 25,14 & 23,61 & 22,44 \\
\hline
\end{tabular}

Médias seguidas de mesma letra minúscula na coluna e maiúscula na linha não diferem significativamente entre si pelo teste de Tukey a $5 \%$ de probabilidade de erro. ${ }^{\text {ns }}=$ não significativo; $*=$ Significativo a $5 \%$;** Significativo a $1 \%$. 
Comparando as cultivares com os controles, observou-se que aos 78 DAE a cultivar IAC OL3 apresentou menor infestação quando foi realizada a aplicação do inseticida, diferindo-se dos demais controles. Para a cultivar IAC 503 nessa época, não observou-se diferenças significativas entre os tratamentos, indicando a necessidade de pulverização do inseticida, que foi realizada aos 79 DAE. Aos 91 DAE verificou-se que a cultivar IAC 503 apresentou menor infestação no tratamento com inseticida sintético, diferindo-se dos demais tratamentos. Para a cultivar IAC OL3, não foram observadas diferenças entre os controles (Tabela 2).

Tabela 2. Desdobramento referente a interação entre os fatores cultivares e controles para as notas de sintomas de E. flavens aos 78 e 91 DAE, Pindorama, SP, safra 2017/18.

\begin{tabular}{lllllll}
\hline & \multicolumn{3}{c}{78 DAE } & \multicolumn{4}{c}{ C1 DAE } \\
\hline \multirow{2}{*}{ Controle } & \multicolumn{3}{c}{ Cultivares } \\
\cline { 2 - 7 } & IAC OL3 & IAC 503 & Teste F & IAC OL3 & IAC 503 & Teste F \\
\hline Testemunha & $29,75 \mathrm{aA}$ & $16,75 \mathrm{aA}$ & $4,30^{\mathrm{ns}}$ & $19,25 \mathrm{Aa}$ & $17,75 \mathrm{aA}$ & $0,15^{\mathrm{ns}}$ \\
Silício via foliar & $18,25 \mathrm{aA}$ & $19,75 \mathrm{aA}$ & $0,03^{\text {ns }}$ & $22,75 \mathrm{aA}$ & $18,75 \mathrm{aA}$ & $0,56^{\mathrm{ns}}$ \\
Silício via solo & $17,00 \mathrm{aA}$ & $19,75 \mathrm{aA}$ & $0,01^{\mathrm{ns}}$ & $17,00 \mathrm{aA}$ & $17,75 \mathrm{aA}$ & $0,01^{\mathrm{ns}}$ \\
Inseticida & $1,75 \mathrm{bB}$ & $10,00 \mathrm{aA}$ & $7,10^{*}$ & $20,75 \mathrm{aA}$ & $1,00 \mathrm{bB}$ & $31,75^{* *}$ \\
\hline Teste F & $13,40^{* *}$ & $1,30 \mathrm{~ns}$ & ----- & $0,30 \mathrm{~ns}$ & $12,68^{* *}$ & ----- \\
\hline
\end{tabular}

Médias seguidas de mesma letra minúscula na coluna e maiúscula na linha não diferem significativamente entre si pelo teste de Tukey a $5 \%$ de probabilidade. ${ }^{\text {ns }}$ : não significativo; **: significativo a $1 \%$.

A ausência de controle do tripes afetou também outros parâmetros avaliados, como os teores de clorofila e \%ARFA. Também causou aumentos na incidência de doenças como verrugose e mancha-preta, contudo, não se observou interação entre os fatores cultivares versus controle (Tabela 2).

Para a avaliação dos teores de clorofila total, não se observou diferenças significativas entre as cultivares, entretanto, comparando os tipos de controles, verificou-se que o inseticida sintético proporcionou o maior valor $\left(48,25 \mu \mathrm{mol} \mathrm{m} \mathrm{m}^{-2}\right)$, diferindo dos demais tratamentos. Esse aumento no tratamento com o inseticida sintético está diretamente relacionado com os menores danos ocasionados pelo E. flavens, uma vez que esse inseto ataca os folíolos causando estrias prateadas e deformações nos folíolos, reduzindo a quantidade de clorofilas. As clorofilas são responsáveis pela captação de energia luminosa, sendo a clorofila a, o principal pigmento dos complexos coletores de luz para as reações fotoquímicas (TAIZ; ZEIGER, 2009). Segundo NOGUEIRA et al. (2010), os altos teores de clorofila indicam maiores taxas fotossintéticas, proporcionando na planta uma maior área foliar e maior crescimento vegetativo. Corroborando as respostas obtidas, verificou-se diferenças também na \%ARFA, sendo o tratamento com inseticida o que apresentou maior aproveitamento da radiação

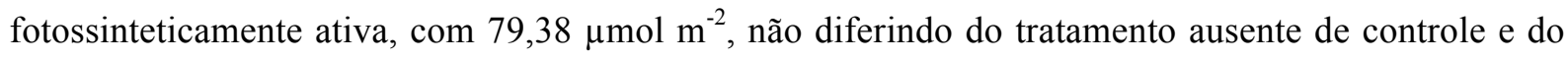
silício aplicado no solo. Esse aumento constatado para o tratamento com inseticida sintético, provavelmente está relacionado aos maiores teores de clorofila e aos menores danos ocasionados pelo 
16 e 17 de agosto de 2018, centro de convenções da FCAV/UNESP - Câmpus de Jaboticabal, SP

E. flavens, culminando em incrementos no rendimento do amendoim, com aumento médio de $88 \%$, quando comparado com os demais tratamentos (Tabela 3).

Independente das aplicações com fungicidas durante todo o período experimental, observou-se que na avaliação de verrugose e de mancha-preta, as cultivares apresentaram diferença significativa, sendo que a cultivar IAC OL3 apresentou as maiores notas de sintomas de mancha-preta e verrugose. Entre os controles utilizados, o tratamento com inseticida sintético proporcionou as menores notas das doenças em relação aos demais controles (Tabela 3).

Como observado nas outras avaliações, na produtividade não diferiu significativamente entre as cultivares. Já entre os tipos de controle adotados pode-se observar que, a aplicação de inseticida apresentou a maior produtividade $4.374,00 \mathrm{~kg} \mathrm{ha}^{-1}$. Já os demais tratamentos não diferiram entre si (Tabela 3).

Tabela 3. Análise do teor de clorofila total, porcentagem de aproveitamento da radiação fotossinteticamente ativa, notas de verrugose, notas de mancha-preta e produtividade $\left(\mathrm{kg} \mathrm{ha}^{-1}\right) \mathrm{em}$ plantas de amendoim submetidas a diferentes controles.

\begin{tabular}{cccccc}
\hline Cultivares (C) & Clorofila & \% ARFA & Verrugose & Mancha Preta & Produtividade \\
\hline IAC OL3 & 38,5 & 64,6 & $3,1 \mathrm{a}$ & $6,2 \mathrm{a}$ & $2.941,5$ \\
IAC 503 & 36,8 & 65,7 & $1,8 \mathrm{~b}$ & $4,2 \mathrm{~b}$ & $2.724,8$ \\
\hline Média & 37,6 & 65,1 & 2,4 & 5,2 & $2.833,1$ \\
\hline Teste F & $2,33^{\mathrm{ns}}$ & $0,05^{\mathrm{ns}}$ & $41,94^{* *}$ & $33,36^{* *}$ & $4,07^{\text {ns }}$ \\
\hline Tipos de Controle (T) & & & & & \\
\hline Testemunha & $32,4 \mathrm{~b}$ & $62,7 \mathrm{ab}$ & $2,7 \mathrm{a}$ & $5,5 \mathrm{a}$ & $2.244,8 \mathrm{~b}$ \\
Silício via foliar & $35,1 \mathrm{~b}$ & $55,7 \mathrm{~b}$ & $2,6 \mathrm{a}$ & $5,7 \mathrm{a}$ & $2.308,5 \mathrm{~b}$ \\
Silício via solo & $34,7 \mathrm{~b}$ & $62,9 \mathrm{ab}$ & $2,8 \mathrm{a}$ & $5,9 \mathrm{a}$ & $2.405,2 \mathrm{~b}$ \\
Inseticida Sintético & $48,3 \mathrm{a}$ & $79,4 \mathrm{a}$ & $1,7 \mathrm{~b}$ & $3,8 \mathrm{~b}$ & $4.374,0 \mathrm{a}$ \\
\hline Teste F & $42,92^{* *}$ & $4,84^{*}$ & $6,40^{* *}$ & $8,35^{* *}$ & $66,68^{* *}$ \\
\hline Teste F (CxT) & $1,01^{\text {ns }}$ & $0,76^{\text {ns }}$ & $0,87^{\text {ns }}$ & $0,72^{\text {ns }}$ & $1,55^{\text {ns }}$ \\
\hline C.V. $(\%)$ & 8,25 & 19,86 & 23,72 & 18,50 & 5,98 \\
\hline Médias & & &
\end{tabular}

Médias seguidas de mesma letra minúscula na coluna e maiúscula na linha não diferem significativamente entre si pelo teste de Tukey a $5 \%$ de probabilidade de erro. ${ }^{\mathrm{ns}}=$ não significativo; $*=$ Significativo a $5 \%$; $* *$ Significativo a $1 \%$.

\section{CONCLUSÃO}

A aplicação de silício via solo ou em pulverização foliar não induziu resistência satisfatória nas plantas de amendoim para controle do E. flavens;

A cultivar IAC 503 apresentou menor número de E. flavens em relação a cultivar IAC OL3;

Entre os tratamentos analisados, o inseticida sintético é o mais eficiente no controle do tripesdo-prateamento.

\section{REFERENCIAS BIBLIOGRÁFICAS}

CONAB. Companhia Nacional de Abastecimento. Grãos. Acompanhamento da Safra Brasileira de

Grãos. Disponível em: http://www.conab.gov.br/. Acesso em: 25 de junho de 2018. 
MICHELOTTO, M.D.; SANTOS, J.F.; GODOY, I.J. Resistência a pragas e doenças em amendoim. In: Tópicos em Entomologia Agrícola VIII. Ed.: BUSOLI, A.C.; CASTILHO, R.C.; ANDRADE, D.J.; ROSSI, G.D.; VIANA, D.L.; FRAGA, D.F.; SOUZA, L.A. pp.105-116, 2015.

NOGUEIRA, P. D. M.; JÚNIOR, D. G. S.; RAGAGNIN, V. A. Clorofila foliar e nodulação em soja adubada com nitrogênio em cobertura. Global Science and Technology, v. 03, n. 02, p.117 - 124, mai/ago. 2010.

RODRIGUES, F.A; OLIVEIRA, L.A; KORNDÖRFER, A.P; KORNDÖRFER, G.H. Silício: Um elemento benéfico e importante para as plantas. Informações Agronômicas nº 134. Pp. 14-20, 2011 TAIZ, L.; ZEIGER, E. Fisiologia Vegetal. 4a ed. Artmed, Porto Alegre, 2009, 820p. 